\title{
An objective undergraduate clinical examination in child health
}

\author{
TONY WATERSTON, JOHN I CATER, AND ROSS G MITCHELL \\ Department of Child Health, University of Dundee
}

SUMmaRY A new type of test used to examine medical students' clinical skills in paediatrics is described. Each student has to circulate round a number of timed stations. At each one he performs a specified clinical procedure-such as history taking, physical examination, urine analysis, and radiological interpretation-and is marked according to his performance. This type of test is objective and can be extended to cover different aspects of clinical methods; it readily informs the student about his progress, and enables the teacher to look critically at his own technique.

'In the long run, the type of evaluation device used determines ... the type of learning activity in which students will engage ... ${ }^{1}$ Put more directly, students learn best the subjects they expect to be examined on. Yet much of what clinical teachers want students to learn is not reliably tested. For example, their abilities to take a history and elicit physical signs are often only cursorily assessed, while such procedures as urine microscopy and the analysis of biochemical data tend not to appear in clinical examinations. In addition, many students dislike the standard formal clinical examination which places them in a most unnatural situation with a patient and provokes considerable anxiety. The view is increasingly being advanced that this type of examination, in which the examiner conducts the student round a number of patients and at the end gives him a single mark or grading for his total performance, is too subjective and tests only a limited part of the student's repertoire. A common criticism of junior doctors today is that they lack empathy and rapport, pay insufficient attention to accurate history taking, and are incompetent at carrying out simple side-room tests. These are all aspects of clinical ability which are inadequately assessed in the traditional examination.

It was for these reasons that the objective structured clinical examination (OSCE) was introduced in $1975^{2}$ and was adapted by us for use in child health.

During their final year at Dundee, medical students in groups of 16 to 20 spend about 8 weeks studying child health, both in the wards at Ninewells
Hospital and Perth Royal Infirmary and in the community, where they attend child health clinics, the area child development centre, schools for the handicapped, and other institutions. At the end of this period they undergo an 'end-of-block' clinical examination, the mark for which contributes greatly to the total in the Final Examination in Child Health. Previously, this 'end-of-block' assessment was a traditional form of clinical examination but it now takes the form of an OSCE.

\section{Objective structured clinical examination}

Each student spends 4 minutes at each of 20 'stations' arranged in a circular fashion around a paediatric ward. Some of the stations are cubicles occupied by patients, others are desks at which the student analyses data of various kinds and answers a multiple choice (MCQ) or short answer question. Half the group starts at zero time; 4 minutes later, when these students have moved to the next station, the remainder occupy their positions, so that all stations are filled. The pattern of stations at a recent examination is shown in Fig. 1.

A bell signifies the end of each 4-minute period and the student then moves to the next station. An examiner with a 'check-list' sits with the patient or parent at stations marked with an asterisk and observes the student's technique but generally does not intervene in the dialogue. Each 'examination station' is succeeded by a 'question station' where the student answers questions on his findings. Figs 2 and 3 illustrate the check list and questions for a history- 
taking station-'take a history from this mother whose child has just been admitted with a convulsion.' Figs 4 and 5 illustrate the check list and questions for an examination station-'examine the cardiovascular system of this child.'
OSCE
4 minutes per station
7 minutes for history taking
2 rest stations

Answer MCQs on answer sheets

Short answer questions (under 10 words each) on paper provided

\begin{tabular}{|c|c|}
\hline Station & Procedure \\
\hline $\begin{array}{l}1 A^{*} \\
\text { (half class) }\end{array}$ & $\begin{array}{l}\text { Mrs McGhee } \\
\text { Take a history from this mother whose } \\
\text { child was admitted with a possible } \\
\text { convulsion }\end{array}$ \\
\hline $1 B^{*}$ & Mrs Cook \\
\hline (half class) & $\begin{array}{l}\text { Take a history from this mother whose } \\
\text { infant was admitted with vomiting }\end{array}$ \\
\hline $2 \mathrm{~A}$ & Questions on 1A \\
\hline 2B & Questions on 1B \\
\hline $3^{*}$ & $\begin{array}{l}\text { Examine the respiratory system of this } \\
\text { child }\end{array}$ \\
\hline 4 & Questions on 3 \\
\hline $5^{*}$ & $\begin{array}{l}\text { Examine the cardiovascular system of } \\
\text { this child }\end{array}$ \\
\hline 6 & Questions on 5 \\
\hline $7^{*}$ & $\begin{array}{l}\text { Perform a routine newborn examination } \\
\text { on this infant }\end{array}$ \\
\hline 8 & Question on 7 \\
\hline 9 & $\begin{array}{l}\text { Examine the specimen of urine } \\
\text { provided }\end{array}$ \\
\hline 10 & Questions on urine \\
\hline 11 & Rest \\
\hline 12 & $\begin{array}{l}\text { Examine the lab report (which relates } \\
\text { to station 9) and answer the questions }\end{array}$ \\
\hline 13 & $\begin{array}{l}\text { Examine the } x \text {-ray and answer the } \\
\text { questions }\end{array}$ \\
\hline 14 & Examine the slide \\
\hline 15 & $\begin{array}{l}\text { Examine the CSF report and answer } \\
\text { the questions }\end{array}$ \\
\hline 16 & $\begin{array}{l}\text { Examine the } x \text {-ray and answer the } \\
\text { questions }\end{array}$ \\
\hline 17 & $\begin{array}{l}\text { Examine the slides and answer the } \\
\text { questions }\end{array}$ \\
\hline 18 & $\begin{array}{l}\text { Examine the haematology report and } \\
\text { answer the questions }\end{array}$ \\
\hline 19 & $\begin{array}{l}\text { Answer the questions relating to the } \\
\text { problem given }\end{array}$ \\
\hline 20 & Rest \\
\hline
\end{tabular}

*Examiner with check list.

Fig. 1 Pattern of stations at a recent examination.
Advantages of this examination. As its name implies, objectivity is probably the main advantage that this examination has over its predecessors but there are several others.

\section{Objectivity}

A standardised technique of marking is used and this is planned in advance. The items of clinical technique which are thought to be most important are included on the check list which the examiner completes for each student. Both history taking and examination are assessed in this way and the student's findings established by an MCQ at the next station.

\section{Flexibility}

Any aspect of clinical technique may be assessed, from diagnostic ability to rapport and from practical expertise to factual knowledge. This means that aspects of the students' ability not previously stressed can be tested in a way which provides effective feedback to the student. In addition, any newly introduced topic of teaching can be separately assessed.

\section{Feedback}

A common complaint from the student after a clinical examination is that he 'didn't know what he did wrong'. If he is to understand his failings and improve his technique, it is essential for him to learn from the examination and we show students the check lists after each OSCE and discuss individual questions. Any deficiencies in particular aspects of teachingfor example, developmental assessment, a notoriously difficult subject to teach-will quickly become apparent and remedies can then be applied. The Table shows the poor performance for urine testing compared with history-taking and radiological interpretation. This clearly indicates a need to improve the teaching of urine analysis for this group of students.

Time

We assess 20 students in 80 minutes. Previously it took twice as long to examine this number.

Table Students' results in individual questions

\begin{tabular}{lllll}
\hline $\begin{array}{l}\text { Question } \\
\text { Marks }\end{array}$ & \multicolumn{3}{c}{ Range (\%) $\begin{array}{l}\text { Mean (\%) } \\
\pm 1 S D\end{array}$} \\
\cline { 2 - 5 } & $\begin{array}{l}\text { Actual } \\
\text { (range) }\end{array}$ & Total & \\
\hline $\begin{array}{l}\text { Examiner's checklist on } \\
\text { history of vomiting }\end{array}$ & $21-38$ & 40 & $54-95$ & $74 \pm 11 \cdot 7$ \\
$\begin{array}{l}\text { MCQ on history of } \\
\text { vomiting }\end{array}$ & $2-5$ & 5 & $40-100$ & $72 \pm 20 \cdot 1$ \\
$\begin{array}{l}\text { MCQ on urine testing } \\
\text { MCQ on } x \text {-ray }\end{array}$ & $1-3$ & 5 & $20-60$ & $41 \pm 14 \cdot 5$ \\
\hline
\end{tabular}


Station

Examiner

(History of convulsions)

Student's name and initials

1. Information obtained

Place tick in appropriate box

\begin{tabular}{llll}
\hline & $\begin{array}{l}\text { Attempted } \\
\text { satisfactorily } \\
(+2)\end{array}$ & $\begin{array}{l}\text { Attempted } \\
(1)\end{array}$ & $\begin{array}{l}\text { Not attempted } \\
\text { (0) }\end{array}$ \\
\hline
\end{tabular}

Name

Age

Siblings (number and age)

FH of convulsions

Birth history: weight

whether asphyxia

milestones

Immunisation status and dates

? Feverish before convulsion

Duration of symptoms before convulsion

Nature of convulsion (general/focal)

Duration of convulsion

Whether single or repeated

Treatment by parents

Treatment by doctor

Mode of delivery

2. Attitude to patient

Consideration of feelings

Attempt to establish rapport

Total $=$
Mark

Below average 0

Average 3

Above average 5

Patient's discretionary mark $=2$

Examiner's discretionary mark $=2$

Fig. 2 Example of the check list for a history-taking station.

\section{Station $2 A$}

Write short answers (under 10 words) to the following questions on paper provided:

1. What condition would you diagnose from the history you have just heard, in order of likelihood?

2. What investigations (if any) would you recommend after admission; give reasons (maximum 3).

3. What treatment would you recommend in future (if any)?

(a) In prophylaxis

(b) If the child becomes feverish

Fig. 3 Example of the questions for a history-taking station.
History taking. Seven minutes are allowed at this station, by providing two stations in parallel on the same 'circuit'. A gap of 1 minute between each student allows discussion to take place between parent and examiner. This period generally appears to be adequate for the limited history that we seek. The type of case chosen is a straightforward onesuch as a wheezy 4-year old, a vomiting infant, or a toddler with a febrile convulsion. Only the parent is present, and we have used both real and simulated parents for this purpose. The great advantage of using the latter is that it allows an acute situation to be simulated-such as a convulsion; this is otherwise difficult if not impossible to arrange. Simulated mothers tend to be from professional backgrounds and are rather more articulate than average, which 
Student's name and initials

Examination of $C V S$

Place tick in appropriate box

\begin{tabular}{llll}
\hline & $\begin{array}{l}\text { Attempted } \\
\text { satisfactorily } \\
(+2)\end{array}$ & $\begin{array}{l}\text { Attempted } \\
(+1)\end{array}$ & $\begin{array}{l}\text { Not } \\
\text { attempted } \\
(0)\end{array}$ \\
\hline
\end{tabular}

Colour noted

Pulses palpated - $(\mathrm{R})$ radial

Femoral

(L) radial

JVP inspected

Fingers inspected

Precordium palpated

Neck auscultated
Axilla
Back
Liver palpated
Ankles checked for oedema
Sphygmomanometer requested

Attitude to patient

Hands washed

Talked to child

Explained procedures

Used child's name

Examiner's discretionary mark 5

Total $=$

Fig. 4 Example of the check list for an examination station.

This patient was a 4-year-old boy with a patent ductus arteriosus. Suggested answers are given in italics together with marks

Write short answers to the following questions on the patient you have just examined.

1. Describe your findings on auscultation.

Grade 3/6 to-and-fro systolic and diastolic murmur, maximal at pulmonary area, conducted to clavicles and well heard also at left scapular area. (Maximum 3.)

2. Name two possible causes for these findings with reasons.

PDA 2 marks, 1 mark for VSD or ASD or other lesions depending on particular findings.

3. What advice would you offer to his parents with respect to (a) activities he can indulge in, (b) prognosis : Anything he feels capable of, very good prognosis after surgery - that is normal life span. (Maximum 4 marks.)

Fig. 5 Questions relating to examination of cardiovascular system. makes the student's task easier. Though the history may be fictitious, the mother sticks closely to actual family details and, in a number of cases, the child has in fact suffered similar symptoms in the past.

In addition to the check list, the mother also comments on each student's performance to provide a 'patient's mark', and additional marks are given by the examiner for the student's empathy and ability to build a rapport. Though we realise that this is not easy in 7 minutes, it is a way of stressing the importance of addressing the child by name and appreciating the mother's anxiety. Occasionally a mother has somewhat exceeded her role by interrogating the student, after he has completed his history taking, on his plans for future management. This indicates a further possible role for the simulated parent, although it is rather disconcerting for the student.

Examination. Typical patients have been a child with cystic fibrosis or asthma (examine the chest), a child 
with a heart murmur (examine the cardiovascular system), and an infant (carry out a routine newborn examination, or do a 6-month development screen on this infant). Again, an examiner with a check list observes the student's technique and can intervene if an infant proves particularly obstreperous. It is important that a substitute should be available in case the patient tires, as is quite likely after a number of examinations. This is especially a problem with infants, but would be so whatever type of clinical examination is being used. A possible solution introduced recently is to provide two stations in parallel (as with history taking) and allow double time for a more-prolonged examination. The student's findings as distinct from technique cannot be observed at this station but are tested by questions at the next station.

Questions. We have used both multiple choice and short answer questions but are tending to move over to the latter because they allow more flexibility and are closer to reality. Examples of contrasting forms of questions after a history-taking station (relating to a child who had a convulsion) are as follows.

\section{$M C Q$}

Which of the following statements is/are true about the history you have just taken:

(1) The infant was vaccinated during the week before admission.

(2) The convulsion lasted over 10 minutes.

(3) The family doctor gave treatment at home before admission.

(4) The child was noted to be unwell before the convulsion took place.

(5) An elder sibling had been similarly affected in the past.

\section{Short answer}

Write short answers (maximum 10 words) to the following questions:

(1) What conditions would you diagnose from the history, in order of likelihood? (maximum 3).

(2) What investigations would you recommend after admission? (maximum 3).

(3) What treatment would you recommend in future (if any)? (a) for prophylaxis (b) if fever occurs.

MCQs can quickly be marked and standard mark sheets are used. Nonmedical staff may mark these, which is a great advantage. Short answer questions must usually be corrected by medical staff and are more laborious, but it is our impression that a better assessment of the student is obtained (marking can be just as objective).
Other stations. A large variety of material has been used. A urine sample for chemical analysis and microscopical examination is always included. Haematuria and glycosuria are easy to mimic, proteinuria and pyuria slightly harder. Casts depend on the availability of a patient with nephritis. Slides or photographs are generally included (for example a purpuric rash, a capillary haemangioma, a battered baby, an infant with talipes, etc.), as are $x$-rays. Laboratory reports of various kinds, fluid balance charts, a prescription 'kardex', and a growth chart illustrating 'fall off' have also been used: the possibilities are endless.

\section{Discussion}

It is difficult to compare results obtained from this type of clinical examination with the more traditional form, since each tests something rather different. OSCE is (or should be) a 'criterion-referenced assessment', whereas the traditional clinical examination is a 'norm-referenced assessment', This means that marks in the latter are related to the average. Thus in a particularly bright group, some students will fail even though they perform competently. The criterion-referenced test is related to the performance of specific objectives which have been set in advance. Hence in this type of assessment a high mark is to be expected if the teaching has been adequate. In the other kind, if marks were high then examiners would object: 'too simple', 'badly set'. Each type of test has its place and the OSCE is more suited to the 'licensing' examination when a clear standard must be reached.

What problems have been encountered in practice in the use of this examination? Examinees have reported difficulties because of the behaviour of patients (particularly infants) after repeated examination. Older children may become uncooperative and babies impossible; it is certainly not reasonable to expect an infant to permit developmental assessment by 20 students in succession. Examination of a patient sometimes has to be curtailed for these reasons, and the OSCE needs to be flexible enough to allow for substitutes. Short answer questions allow this more readily than MCQs. Another criticism has been of the check lists, which do not always cover those procedures which each examiner thinks important. This however has led to useful discussion on this very question: which procedures are the ones we must stress in teaching? In history taking, examiners have felt that parents may not give quite the same history at the end of a session as at the beginning, but become more practised at reproducing the same version unprompted. Mothers may need 
reminding to keep their answers short and to the point. Examiners generally have not resented their less active, background role although there is still the temptation to intervene. The unreality of the interviews has been mentioned but students do not seem to find this a problem. More examiners are required in this examination than in the normal sort (usually 5) but all grades of staff, including house officers, may be used (a good educational experience for them). Previously 2 consultants were occupied for a whole morning, whereas now 3 or 4 are occupied for 80 minutes each.

The preparation of the examination is extremely time-consuming, particularly at the beginning, as all the data, questions, and check lists need to be collated in advance and tailored to the individual histories or patients. However, the time required becomes less and less as a 'bank' of material is built up after each OSCE. A department of medical education is not essential for the exercise. Although we obtained useful advice from our department, the detailed setting up was carried out in the Department of Child Health. Efficient secretarial assistance in preparation and in marking is essential.

Students have complained about the lack of time for a full physical examination, particularly in the case of infants, and about the wording of MCQs. For these reasons we now allow double time for infant examination (by providing two stations in parallel) and have replaced many of the MCQs with short answer questions. In general, students are happy with most stations and do not feel rushed. Many prefer this type of examination to the traditional form. They do not find 7 minutes too short a time for limited history taking and many finish (or dry up) before the allotted time.

From our experience with OSCE, we consider that it has great potential for both undergraduate and postgraduate assessment and that all university departments should consider its introduction, at least experimentally.

We thank Professor R M Harden and staff for helpful advice and Mrs P Easton for marking most of the MCQs, and for statistical assistance.

\section{References}

1 Guilbert J-J. Educational handbook for health personnel. Geneva: World Health Organisation, 1977.

2 Harden R McG, Stevenson M, Downie W W, Wilson G M. Assessment of clinical competence using objective structured examinations. $\mathrm{Br}$ Med J 1977; i: 447-51.

Correspondence to Dr A Waterston, Department of Paediatrics and Child Health, University of Zimbabwe, PO Box A178, Salisbury, Zimbabwe.

Received 8 November 1979 